\title{
Living with disasters: social capital for disaster governance
}

\author{
Maria de Lourdes Melo Zurita, Brian Cook, Dana C. Thomsen, Paul G. Munro, \\ Timothy F. Smith, and John Gallina'
}

This paper explores how social networks and bonds within and across organisations shape disaster operations and strategies. Local government disaster training exercises serve as a window through which to view these relations, and 'social capital' is used as an analytic for making sense of the human relations at the core of disaster management operations. These elements help to expose and substantiate the often intangible relations that compose the culture that exists, and that is shaped by preparations for disasters. The study reveals how this social capital has been generated through personal interactions, which are shared among disaster managers across different organisations and across 'levels' within those organisations. Recognition of these 'group resources' has significant implications for disaster management in which conducive social relations have become paramount. The paper concludes that socio-cultural relations, as well as a peoplecentred approach to preparations, appear to be effective means of readying for, and ultimately responding to, disasters.

Keywords: Australia, disaster governance, floods, local government, Queensland, social capital, subsidiarity

\section{Introduction}

The concept of 'social capital' has emerged as a key area of discussion in disaster research (Pelling, 2003; Nakagawa and Shaw, 2004; Pelling and High, 2005; Aldrich, 20I2a), owing primarily to the widely accepted premise that 'natural' disasters can be best defined as the entanglement of natural hazards with vulnerable populations (Susman, O’Keefe, and Wisner, I983; Varley, I994; Hoffman and Oliver-Smith, I999; Pelling, 200I; Wisner et al., 20I4). Social capital, broadly understood as the 'resources resulting from social cohesion that may be drawn upon by individuals for collective action and collective benefit' (Reininger et al., 20I3, p. 56), is viewed as a critical component of mechanisms to help affected populations respond more effectively to disasters (Murphy, 2007; Bihari and Ryan, 2012), as well as aiding their recovery during post-disaster reconstruction phases (Nakagawa and Shaw, 2004; Hawkins and Maurer, 20IO; Aldrich, 20I2a). Much research on social capital and disasters has focused on different methodologies to try and measure the presence of social capital during the response (that is, during the event) and recovery (that is, after the event) phases of a disaster (Wisner, 2003; Murphy, 2007; Hawkins and Maurer, 2010; Aldrich, 20I2a), as well as on how it might be enhanced during planning and preparation for a disaster (that is, prior to the event) (Wisner, 2003; Allen, 2006; Bihari and Ryan, 2012). 
For the most part, existing research has concentrated on affected or potentially affected populations, with an emphasis on building or understanding community disaster resilience (see, for example, Cutter, Ash, and Emrich, 20I4). Missing from these studies, however, is consideration of the potential role of 'social capital' within formal emergency response and governmental agencies: how social networks and connections within and across these organisations might shape effective preparations for and responses to disasters.

This paper, drawing on a case study of flooding in southeast Queensland, Australia, in 20IO-II, addresses this lacuna by providing insights into how 'social capital' cuts across the prevailing, reductionist interpretation of disaster management. Through more inclusive accounting of the social and human relations that span organisations, spaces, and time at the local government level, it provides a network understanding of the human relations that constitute disaster governance.

Disasters generally are events where day-to-day governance is disrupted and where a large range of different actors — governmental and non-governmental-are required to (re)act (Melo Zurita et al., 20I5a). Formal disaster governance has been, historically and legally, the prerogative of state governments, especially in developed world federated nations such as Australia (Britton and Wettenhall, I990). While state levels of government often have maintained core legislative authority, there have been noticeable shifts recently in the allocation of responsibility to other levels of government (Commonwealth and regional/local), as well as to the non-governmental and private sectors (Melo Zurita et al., 20I5a). These shifts challenge long-standing notions of disaster management rooted in policy made in the I970s (Gill, I979; Wettenhall, I979; Dynes, I983) and mostly reflect a decline of the 'command and control' approach (Neal and Phillips, I995). In addition, they are intertwined with a neoliberal-influenced transition from 'government to governance' (Wisner, 200I; Oliver-Smith, 2015), as governments at all levels reduce or revise their services and a more complex governance melange emerges (Tierney, 2012).

In this context, private and non-governmental organisations, along with local government and individual residents, are increasingly expected to bear additional responsibility and to fill voids that traditionally have been occupied by 'big government' (Kaika, 2003; McConnell and Drennan, 2006; Ostrom, 20I4; Melo Zurita et al., 2015b). These changes are not simply an evolution of emergency management praxis prompted by 'natural' hazards, but also represent a response to dynamic politi$\mathrm{cal}$ and economic changes. As such, attempts to improve disaster governance- - that is, the actors, institutions, and processes that shape decisions and actions geared towards disasters - necessitate an examination of the management approaches and the social relations that underpin, and possibly predetermine, them. This paper focuses specifically on the local government sector in the state of Queensland, Australia, and assesses how it has responded to broader modifications of disaster governance.

Scholarship over the past few years has advocated a rebalancing of power, in which the authority and role of a centralised state is shared with a diverse set of actors and agencies (Kendra and Wachtendorf, 2007; Leonard and Howitt, 20IO; Wachtendorf, 
2013). This builds on earlier work that recognises the important part that 'emergent groups' - collectives of private citizens that are not formally institutionalised-play in responding to disasters (Stallings and Quarantelli, I985; Majchrzak et al., 2007). This line of thought advocates broadly that disaster managers should embrace a diffuse organisational response nested within a broader centralised governmental structure. Via this model, successful disaster governance "emerges" from the distributed action of independent agents rather than being "engineered" by a central command and control entity' (Leonard and Howitt, 20Io, p. 378). A more recent account by Cook and Melo Zurita (2016) suggests, however, that some form of command and control is a necessary but insufficient dimension of disaster governance, prompting the need to reconsider how this established approach can complement, and be complemented by, emergent forms of disaster governance in the context of catastrophic events. In particular, if a 'diffuse organisational response' is considered as optimal in some settings, then the internal capacity of organisations active in responding to disasters requires analytical attention; specifically, the experts and expertise that shape disaster management culture become a central component of efforts to understand management systems, their persistence, and how they might be altered (Cook, 20I5). The ability to respond to disasters is not an innate characteristic of these organisations; this paper argues that a 'social capital' lens provides a useful investigative means of comprehending their internal cultures and dynamics.

The seminal work of Robert Putnam (I995, 2000) on social capital is a fundamental starting point for much of the literature on social capital and disaster governance (see, for example, Adger, 2003; Pelling, 2003; Pelling and High, 2005; Murphy, 2007; Hawkins and Maurer, 20I0; Aldrich, 20II, 20I2a, 20I2b; Dussaillant and Guzmán, 2014). Putnam (I995, pp. 664-665) defines social capital as the 'features of social life - networks, norms and trust - that enable participants to act together more effectively to pursue shared objectives', with networks being understood as the connections between people, norms as the informal laws that govern exchanges in daily life, and trust as how people anticipate how others will behave in the future (Aldrich, 20I2). The presence of social capital, though, is not axiomatically benign; in some situations it can reinforce systems of discrimination or the marginalisation of groups (Aldrich, 20I2). In recognition of this variability, analytical distinctions between bonding and bridging social capital have been developed. Bonding social capital refers to trust and relations within a network of people who see themselves as similar in terms of identity, whereas bridging social capital is composed of relations of respect and reciprocity between people from different socio-demographic groups (differing, inter alia, by age, class, and ethnic group) (Szreter and Woolcock, 2004; Hawkins and Maurer, 2010; Wolf et al., 20I0). Szreter and Woolock (2004) also propose a third category of linking social capital, which is articulated as social networks operating across formal or institutionalised power or authority gradients in society. In other words, it is the extent to which individuals are able to develop relationships with other individuals and institutions that have relative power over them (Hawkins and Maurer, 2010). 
Given that the formal disaster governance sector involves diverse individuals, frequently in different hierarchical positions, the notion of bridging and linking social capital contributes analytical perspectives to this inquiry into socio-cultural relations-bonding capital is less relevant to this paper as it tends to relate to kin, rather than professional, relationships. This examination is interested in how different disaster managers, across different organisations and roles, and in different positions in the bureaucratic hierarchy, contribute to the development of the networks, norms, and trust that influence their ability to respond to disasters. Specifically, the spotlight is on how this social capital, which arises from and is reinforced by practise and drill events, allows for relatively sclerotic governing bodies to transform and adapt during disasters.

To explore socio-cultural relations using social capital, the floods in southeast Queensland in 20IO-I I were selected as a case study. This research appraises changes to disaster laws, authority, and planning at the state level, as well as recent interagency practise drills and networking activities, to probe these socio-cultural relations. In the parlance of social capital, it shows how bridging and linking social capitals have developed within and across formal disaster governance actors. This context demonstrates how social capital configurations across multiple organisationsa pan-organisational social capital — can be an effective means of preparing for and responding to disasters. In addition to this conceptual contribution, the analysis also offers empirical insights into what local governments do as part of preparations for disasters, an area of research that has been largely neglected in Australia (Melo Zurita et al., 20I5a) and elsewhere (Col, 2007).

The paper begins with an overview of disaster governance in Queensland. It goes on to investigate the roles of governmental and non-governmental actors that are part of the disaster governance system, reviewing how they have changed since 20 Io. Next it assesses system operations across multiple agencies, actors, and geographies, and then looks at the 'mock disaster' exercises (simulations of disasters) performed in southeast Queensland. It concludes that, while it is difficult to plan for a disaster in a specific geographical area, it is possible to plan for the group of people that will be required to coordinate the disaster. A people-centred approach to building social capital among these actors can help to provide an avenue for altering and refining responses to disasters when they arise.

\section{Disaster governance in the state of Queensland, Australia}

Queensland experiences a wide range of natural disasters. In the tropical north, cyclones are the most prevalent hazard, whereas flooding, and to a lesser extent bushfires, are more common in the southeast. Notably, the floods in 20IO-I I resulted in 33 deaths, and, with an estimated reconstruction cost in excess of AUD 5 billion, are credited as being Australia's most expensive disaster to date (van den Honert and McAneney, 20I i; Queensland Commission of Inquiry, 20I2). The effects of climate change are expected to amplify the frequency and intensity of disasters in the region (Thomas et al., 20II). 
The Disaster Management Act $2003^{2}$ is the key regulatory instrument for disaster management in Queensland and includes the main objective of helping communities to 'mitigate the potential adverse effects of an event; . . prepare for managing the effects of an event; and ... effectively respond to, and recover from, a disaster or an emergency situation'. This legal instrument is by no means a static body of regulation, having been in a constant state of revision and incremental modification (in 2004, 2005, 2008, 2009, 20II, 20I2, and 20I4) since its initial drafting in 2003. The most significant recent change has been the creation of the Office of the InspectorGeneral Emergency Management, whose functions include monitoring, reviewing, and reporting on disaster governance arrangements, local council plans, and local and district group activities. The Office of the Inspector-General Emergency Management reports directly to the relevant minister (Disaster Management Act, section IA), which illustrates the incorporation and consolidation of disaster management in the core business of government.

Current disaster governance in Queensland is based on hierarchical arrangements across the tiers of government associated with geographical areas. It is a nested governance approach, where decision-making is distributed across a hierarchy of institutions, in part as a strategy to address the dynamics of disasters that can manifest unpredictably, at a range of different scales (Wyborn and Bixler, 20I3). This is depicted in the pyramid structure shown in Figure I, where the national government forms the base. Although disaster management is legally a state or territory responsibility, the national government is active in disaster management through the provision of funding for emergency management training, relief and forecasting information on potential disasters (Britton and Wettenhall, I990; Handmer, Keys, and Elliot, I999). Many of these measures were formalised through the joint CommonwealthState National Disaster Relief and Recovery Arrangements (NDRRA), drafted in 1997 (Biggs, 20I2; Melo Zurita et al., 2015a). These funding arrangements are particularly important for Queensland owing to the frequency and severity of disasters; approximately 90 per cent of the NDRRA budget has gone to the state. During extreme disasters, the federal government also deploys periodically the Australian Defence Force to support emergency response (Fetchik, 20I2). Thus, while disaster management remains under the legal authority of state and territory governments, the federal government is a key actor, especially in terms of the provision of fiscal resources (Eburn, 20II).

The review of the NDRRA in May 2015, however, recommended a reduction in funding to states in the near future, with a shift from recovery to mitigation, as well as greater budgetary transparency. Consequently, other levels of government and non-state actors will need to shoulder a greater share of disaster recovery costs, providing incentives for increased management effectiveness, mitigation, and insurance against risks. In essence, there has been a change in disaster responsibility, with a shift towards lower levels of government (Melo Zurita et al., 20I5a).

Figure I is organised according to geographical area covered (largest to smallest): federal state, district, and local. Each of the tiers beneath federal has a disaster 
Figure 1. Queensland's disaster management structure

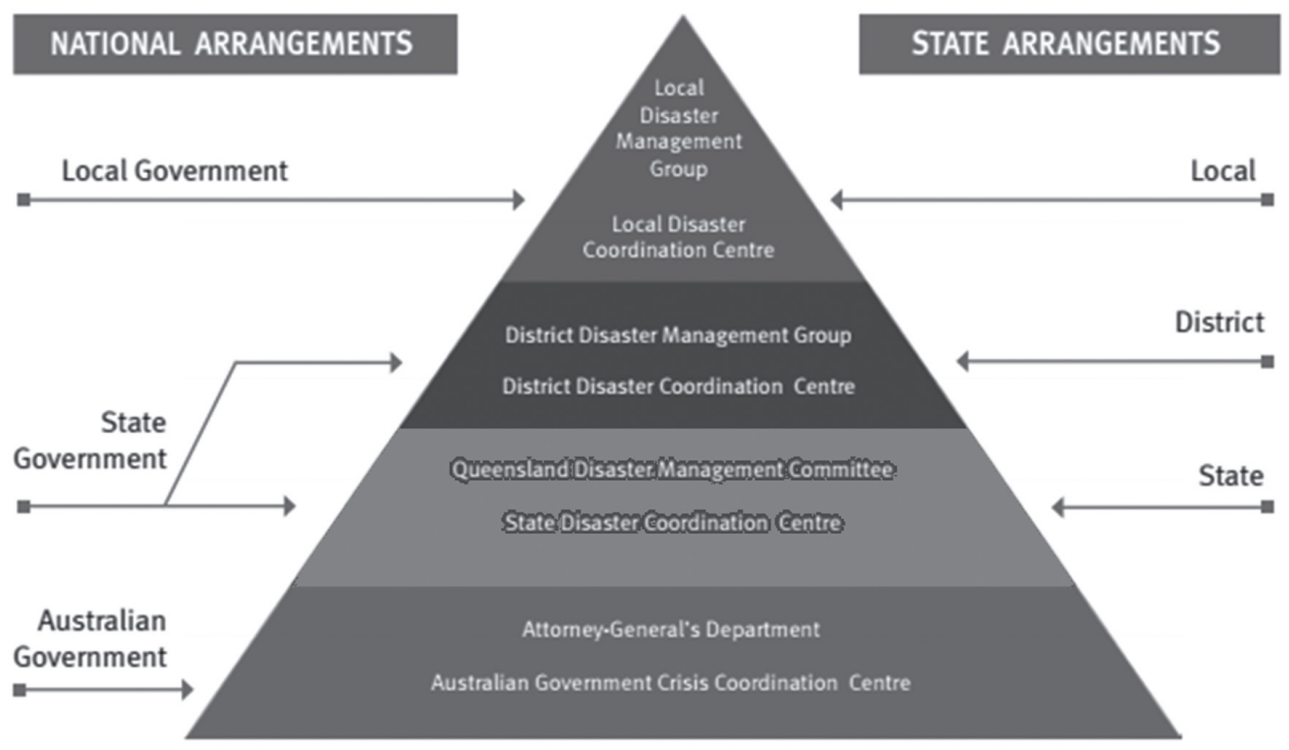

Source: State of Queensland (2016). Reproduced in accordance with https://creativecommons.org/licenses/ by/4.0/deed.en (last accessed on 26 September 2017).

management group (DMG), which is enacted during an event through the establishment of a disaster coordination centre (DCC). These centres become focal points of decision-making and communication during a disaster. Whether each (or all) of these DCCs are activated depends on the size, scale, and type of disaster. A small-scale disaster might be addressed adequately by a local DMG, whereas a large-scale disaster will require local, district, and state DMGs, as well as support from the federal government.

Queensland disaster governance is unique in Australia because of the existence of a district level for disaster governance. While local and state tiers reflect existing governmental structures, the district tier is ephemeral, becoming active only during a disaster. It is ascribed in the Disaster Management Act 2003 that 'District groups ... should provide local governments with resources and support to help the local governments carry out disaster operations'. District DMGs are led by a chairperson (who is also the District Disaster Coordinator), appointed by the Commissioner of the Queensland Police Service, and are composed predominantly of representatives of state agencies (State of Queensland, 20I6). During a disaster, the district DMG coordinates the collection and prompt dissemination of relevant information to and from local DCCs and the state DCC.

\section{Case study and methods}

A social capital analytic is applied to a case study of Queensland to explore the socio-cultural relations that shape disaster management in formal disaster response agencies, critically appraising the changing approaches and structures in the state's 
disaster governance. The evaluation provides the empirical basis for a discussion of disaster management practise and practices. In particular, the paper examines how changes in the way disasters are understood and prepared for have facilitated new 'shared social resources' among disaster managers across different organisations.

The assessment draws on I4 semi-structured interviews with participants, conducted throughout 20I4 and 2015. These experiential experts include staff from local government and other disaster management agencies (such as the Queensland Fire and Emergency Services and recovery agencies) in Moreton Bay, Noosa, and Sunshine Coast local government areas (LGAs). All I 4 interviews were transcribed, coded, and analysed to identify key themes and trends in changes in disaster governance approaches. These interviews are coded as II, I2, I3, etcetera, and were supplemented by participant observation in local government disaster training (courses and exercises) and disaster coordination centres.

\section{Results}

A crucial human capacity has emerged in the context of changes in disaster policy and practices in Queensland, yet it is one that is intangible and for which it is difficult to account: the personal relations that cut across disaster managers as they prepare for and respond to events. It is a form of pan-organisational social capital that has assisted disaster managers in responding to crises in an effective and flexible manner. Historically, disaster governance has been receptive to the intangible social relations among disasteraffected populations (Wisner et al., 20I4; Krüger et al., 20I5), but, in the opinion of the authors, this openness has not be applied reflectively. This paper contends that there is value in internalising and recognising the benefits of the social relations that function among disaster managers. Recognition of such social capital will help agencies and managers to vocalise a vital yet easily overlooked component of disaster governance: the cultures, networks, norms, and trust that arise among different formal disaster governance actors, which enables them to respond effectively to disasters.

Two fundamental changes have allowed this 'social capital' to emerge in the state of Queensland. The first is the transition to a nested governance approach, whereby more responsibility has been given to local councils. The second is the normalising of disasters through mock events, which has helped to identify 'disaster champions' (that is, people that adopt leadership roles during an event), develop skills, and create a shared sense of identity among disaster managers. Vitally, through these training exercises, disaster managers appear to have become cognisant of the relations on which they draw, and, as a result, are able to acknowledge one another's knowledge and expertise.

\section{Nested governance}

Queensland has adopted a nested form of disaster governance, with different roles and responsibilities spread across local, district, state, and federal tiers. It is an approach that is credited with offering superior coordination because it is able to address better 
the uncertainties of disaster impacts and differing institutional capacities and geographies. Although the Queensland District Disaster Management Guidelines (Emergency Management Queensland, 20I2) does not provide a specific rationale for the establishment of a district level, it facilitates the coordination and delivery of response mechanisms in two important ways. First, because Queensland is a large state geographically (I,852,642 square kilometres), with its capital city, Brisbane, situated in the southeast corner, the implementation of a DMG at the district level helps the state government to maintain influence across a relatively dispersed population. Second, LGAs in Queensland vary greatly in terms of population and institutional capacity and capability. For instance, the LGA of the City of Brisbane has a population of more than one million, whereas the LGA of the Shire of Croydon has a population of approximately 300 people (Australian Bureau of Statistics, 20I0). The establishment of a district level is, therefore, a form of amalgamation attuned to disasters that supports smaller and poorly resourced councils as well as neighbouring councils affected by such events. The Cairns Disaster District area, for example, covers is local government councils, whereas the Gold Coast Disaster District covers just one (Gold Coast City Council). The Sunshine Coast and Noosa Councils both fall under the Sunshine Coast District, while Moreton Bay is the sole council under Redcliff District. There are 23 district areas across Queensland in total.

Each local government in the state is required to prepare a local disaster management plan, and to establish a DMG that becomes active during a disaster. Some local councils, particularly those affected by recent floods (such as Bundaberg Regional Council and Sunshine Coast Council), have now allocated full-time personnel to all phases of disaster management (from mitigation to recovery). In Queensland, local governments have emerged as the lead agency in responding to flooding and have found themselves playing a central role in disaster management. As one research respondent $\left(\mathrm{I}_{5}\right)$ noted:

I mean, for local government, local councils, with any event, councils are always the first there. They are there through the coordination. . . They're always last to bail out. . . . Local government is at the pointy end of the community. They're there before, they're there during, and they're always there after.

This comment evokes the principle of subsidiarity, which recognises that decisionmaking is ideally devolved to the most competent level of a structure (Melo Zurita et al., 20I5a). This principle that has become embedded in disaster management policy (see, for example, Council of Australian Governments, 20I I; McLennan and Handmer, 2014).

Councils are increasingly seeking to perform their legislated disaster functions in a coordinated and consultative manner, as opposed to one shaped by 'command and control' (Singh-Peterson et al., 2015). Outcomes are ultimately mediated by the needs of the disaster group membership and the community, as well as by other important considerations such as location-specific priorities. Nonetheless, the diversity 
in the geography, resources, size, and staff of the councils has prevented a standardised allocation of responsibility among them. A 'mismatch' is evident across Queensland, in which some councils have the capacity to fulfil their role at the 'pointy end' of the pyramid (see Figure I), whereas others rely more heavily on the state to provide services. Overall, Queensland's Disaster Management Act 2003 states that 'local governments should primarily be responsible for managing events in their local government area', while the state and district levels are characterised as playing a more supportive role. This is a substantial change from previous approaches, in which the state government was the main actor.

It was from this point that local governments assumed responsibility for integrating disaster management into their operating structures. In practice, the degree to which disaster management has been integrated into councils varies, with some making it part of their core activities, and others adding it to existent arrangements. The legislation implies how DMGs should be structured at the local government level, but it is really up to the local governments to develop their strategies and to comply with these requirements.

Owing to these changes, it is informative to enquire as to what local governments do now, and how they plan for disasters that are unpredictable and dynamic. Local councils in southeast Queensland, especially in the Sunshine Coast region, have responded to this challenge by normalising disasters through repeated mock drills. These have not only provided opportunities for skills-based training, but also have served as focal points for the development of valuable socio-cultural relations among the disaster managers and agencies involved.

The nested governance approach in Queensland has sought strategic devolution. It has aimed to shift responsibility for emergency response from the state government tier (which, historically and legally, has had central responsibility) to the local government, while at the same time ensuring that wider governance scaffolding remains in place should assistance be required (that is, from the district, state, or federal level). This structure has contributed to a situation in which disaster expertise is developed within the locality likely to experience the disaster. This is relevant not just for local capacities, but also in developing localised networks. These networks can be described as the creation of pan-organisational forms of social capital, bridging and linking across different agencies, such as local governments and other relevant locally-based organisations, including the police and volunteer emergency responders. The development of this pan-organisational social capital has not occurred by chance, but rather has been facilitated by the introduction of mock disasters, which have allowed disaster managers, across positions, organisations, and hierarchies, to work together during simulated events.

\section{Local capacity: normalising disasters through mock events}

Disasters, by definition, are rare unfolding crises, meaning that opportunities to learn 'on-the-job' are limited. It is a challenge, therefore, to ensure that staff members of all agencies are able to fulfil their 'temporary', yet vital, roles competently. Consequently, 
the development of simulated disaster events has presented opportunities for experimentation in hypothetical, chaotic environments. As one disaster manager $\left(\mathrm{I}_{3}\right)$ noted:

We do not have to have a [real] event to recognise [an issue or a gap in the arrangements], we can do an exercise and practise a scenario that we have not done before. That is going to raise up different issues than the ones we are used to.

Each mock event varies considerably. They focus on a range of potential scenarios from 'natural' disasters such as bushfires and floods to technological disasters such as chemical spills. Given that it is not uncommon for local government offices or personnel, inter alia, to be affected by disasters (Kendra and Watchendorf, 2003), sometimes these exercises are run with the assumption that there is no longer a supply of power and water to the local DCC. Participants involved in these scenarios must expect the unexpected, and be creative in their responses. One example is a scenario modelled on a railway disaster, which two of the authors observed, that was conducted in 20I4:

On the $14^{\text {th }}$ October 2014 [a freight train] enters the Nambour Central Business District. [Meanwhile in Nambour] a truck carrying an excavator . . accelerates without considering the height restriction warning [and] collides with [a rail bridge] causing a deformation in the rail track. The driver of the freight train observes the damaged rail on the approach ... and commences to power down and then apply emergency breaking to reduce the impact of derailing the train, when an empty low loader [railway] container derails [subsequently] causing a flow on effect of wagons to follow each other off the overpass onto the roadway below, into nearby business premises and carparks. The overhead [powerlines] are pulled down by derailing wagons causing fire damage to nearby business dwellings and parked vehicles. The mixed freight train loads comprises enclosed tankers loader with compressed flammable gases, acetylene, nitrous oxide, and containerised contaminants including bleach powdered, fertilisers and industry strength cleaners (Sunshine Coast Council, 20I4).

The narrative above was created by local and district DMGs in Sunshine Coast and served as a mock event at which a disaster management group was activated and a disaster coordination centre was in operation. Each of the actors involved in disaster response sent a representative to the DCC, including the Queensland Ambulance Service, the Queensland Fire and Emergency Services, the Queensland Police Service, the Red Cross, and the media. In one room, all council staff with a role during disasters were transferred from their day-to-day positions to disaster-oriented roles. For instance, people from the urban planning and infrastructure departments were engaged in intelligence, providing maps of road closures in the disaster coordination room, while people in charge of running the website for the council launched an online disaster hub and processed updates on information coming through. Typically, 'hot debriefs' occur after these events at which feedback from observers and local council staff is provided to the agencies. This feedback is analysed and considered 
for future exercises, as well as informing local and district disaster management plans. One respondent (I2) reflected on this iterative process:

Constant refinement, constant trial and seeing what really works, then you may get a new personality, somebody from the council volunteers to work within the coordination centres and they have this area of expertise that we haven't used before, so we better take advantage of that. Or you lose that piece of expertise. So you do have to adapt to that as well. It is a fluid environment all the time, which is what makes it so interesting.

In addition to providing staff with general training, research participants noted that these events afforded excellent opportunities for pinpointing disaster governance champions. They observed that this process often was counterintuitive: quiet, unassuming personnel would frequently rise up during these events, demonstrating the necessary skillset and temperament to be able to deal with complex and evolving situations. Relatedly, staff who were assumed to be potential disaster governance champions, sometimes revealed themselves to be poor points of contact. As one research participant (II) pointed out:

In those situations [mock disaster exercises] you may get someone who is an admin person, a typist, and they could be sensational in an important position in the coordination centre. Whereas someone who is a branch manager could be making coffees for people and making sure people are fed. It is just a complete flip side. It is a case of finding what person suits what position. You will see halfway through events people crumbling. It is just a point of saying right, you are not right for that position, come this way I'll give you this job instead. Easy, no worries, it keeps everybody happy that way.

In essence, these mock events are an opportunity for learning, and therefore all local council staff are encouraged to participate in disaster training and exercises (regardless of their daily jobs) as well as to assume a variety of roles beyond their job description. Aside from identifying individual champions, these mock events are seen as integral networking platforms, what might be described as the development of bridging social capital, as they offer chances to interact with multiple branches of the councils and with other local disaster actors (such as the police and state emergency services), and to get to know one another's expertise. This speaks to the core notion of 'trust' in the social capital literature: these mock events help people to anticipate how others might behave in future disaster scenarios. In southeast Queensland, furthermore, various councils have collaborated to exchange experiences and to address recommendations made by the Queensland Commission of Inquiry (2OI2). As one participant (III) put it, 'it is . . about coming together to discuss ideas, to share innovations'. It is a process of social learning: learning from and with others, which provides a basis for collective and adaptive decision-making (Thomsen, 2008). Learning not just occurs via the mock exercise developed, but also through the nuanced interactions between different participants. Creating a network of likeminded 
people seems to be essential for approaching the previously mentioned dynamism of the Disaster Management Act 2003, which emphasises necessary organisational readjustments, as well as, and perhaps more importantly, the ability to respond to the intensity and types of disasters that the region has encountered.

Training exercises are not just a platform for spotting disaster champions, but also a critical opportunity to build the networks of people that are needed in a coordination room during a disaster response. In sum, these events build social capital, which in turn results in human and organisational capacity. The approach is process orientated, rather than goal orientated (Thomsen, 2008), and hence is ongoing. Consequently, these training exercises are arguably less critical in terms of how they build specific human capital in individuals (such as disaster response skills), than in their broad development of social capital.

The focus on developed capacities at the local level represents the crux of a subsidiarity approach to disaster management, one that favours the strategic devolution of powers. Pan-organisational responses across scales can function effectively when people know their position in the system. Reflections on recent disasters, such as the southeast Queensland floods in 20IO-II, were less about who took the lead, than how people were able to transition to their temporary roles effectively-a reflection of historical networking processes within the region. One participant (III) underlined that:

In a real event, it kind of starts with maybe one phone call and the whole thing just escalates from there. So having done the exercise you then realise that that training was really important. Because when the chips are down and it's a real event everything drops into place quickly. Because people know what their role is. They know what they need to do and they just get in and do it.

This quote speaks to the three core aspects of social capital: networks, norms, and trust. There is an existing collaboration of people (networks), who know what they need to do (norms), and have the knowledge that they can rely on others in their network (trust). Overall, this process of normalising disaster governance through mock events has been credited with providing the critical foundation for local councils during disasters. In what might be described as democratised performance, the councils have created a constructive learning space that allows a range of individuals to interact and influence governance through the development of socio-cultural relations. As the research participants underlined, owing to their training, things just 'click into place' during a disaster. There is no need for a strong top-down hierarchal structure to be imposed; people implicitly 'know what they need to do and they just get in and do it'.

Thus, even though capacities, skills, and resources are valued as necessary to promote action and adaptation, the starting point seems to be strongly related to the idea of letting people self-organise, and to use their own resources, when available, to take decisions and to plan. This represents, therefore, a democratisation in its 
broadest sense: that relevant disaster governance champions are able to realise their potential within a complex system and under pressure. The focus on networking between different disaster managers, and the identification of disaster champions, regardless of their existing position within the governmental bureaucracy, are examples of the development of bridging and linking social capital. A constructive space has been created to allow for the creation of an effective disaster management culture, in which a team is able to transcend different organisations and existing hierarchies.

\section{Social capital in disaster governance}

This case study highlights an approach in which a disaster governance structure is put in place, but it is not the formal structure per se that makes the process work, but rather, it is the people, the networks, and the experiential training that makes disasters manageable. It is not the formal structure that is adaptive, but the people in the structure who are free to be adaptive within a more fluid structure. This freedom goes beyond the individual and is emergent through the evolving networks and shared understandings of disaster governance that accompany the training exercises and infuse the resulting capacities for disaster management. One participant ( $\left.\mathrm{I}_{4}\right)$ stated:

I think it's a close-knit family when it comes to disaster management. It's a bit of a team sport. So we all know each other. We all have each other's contact numbers in our phones. It's understood if we needed to talk to each other at two o'clock on a Sunday morning, then we would.

Another (III) added:

I've developed a fabulous relationship with just about all of those people [other local disaster management actors]. I would feel very comfortable in being able to pick up the phone, as would my colleagues, and talk to those people. They would know that if I rang them to say I've got an emergency and I need your assistance right now, it would happen.

The emerging disaster management culture, most obvious at the local level in southeast Queensland, has been facilitated by the increased responsibilities that have been ascribed to local governments. Social capital, in this case, helps to expose the materialisation of fluid networks of relations among disaster managers and agencies. It also seems to help shape who is responsible for particular roles, as well as to create localised networks of disaster management actors who are able to emerge collectively when needed to respond to unexpected events.

An important 'actor' in this context is Queensland's frequent hazards: bushfires, cyclones, and floods. While the 20I0-I I floods were an inflection point, the regular bushfire and flood disasters in the region appear to have provided sufficient economic and political capital, as well organisational impetus, to ensure that learning activities continue. In a sense, these disasters represent natural capital, in that they 
ensure there is sufficient motivation for the mock exercises. The relevance of the exercises is reinforced by recurrent disasters. The outcome is not so much the development of plans (on paper), but a pan-organisational social capital (Cook and Melo Zurita, 20I6).

This is an outcome that is under-reported in the literature. For instance, McConnell and Drennan (2006, p. 67), although sympathetic to training exercises, have suggested that their efficacy is limited because 'such exercises cannot be conducted in every public institution for every possible scenario' and 'crises do not respect organisational training and planning'. Such a critique, however, at least in this case, underestimates, and possibly demeans, the ancillary impacts associated with training. It need not be strictly about predicting and preparing for specific disasters, nor about preparing particular individuals_-indeed, people change jobs and occupy different roles at different stages of their careers - but rather it is about the socio-cultural relations and capitals that can be built during the periods between disasters. The resulting social and institutional capitals, according to the respondents, are a principal aspect of effective disaster management.

A functional, local system for disaster governance suggests the emergence of human relations as a critical component of disaster response competencies. In turn, this reflects a more widely accepted disaster governance model for the sustainability of communities during and following disasters. Given the legislative responsibilities placed on local governments by the Disaster Management Act 2003, one would expect local governments to be consulted often and widely, even if legislation is enacted at the state level. The managerial dynamism promoted after the southeast Queensland floods in 20IO-I I allowed local governments to develop a series of networks that enables the emergence of a disaster management culture that engenders learning and capacities. The formal allocation of responsibilities in the Disaster Management Act 2003 seems to be in concert with such a process, but the establishment of state-driven standards and performance measures in 2012 could affect the organic development of this social capital. The overlaying of a new level of government compliance measures may disrupt less formal, but equally important, local networks, their capabilities, and community connectedness. How these forms of governance interact will be a vital aspect of future disaster governance in the region.

\section{Conclusion}

This paper shows that, although it is difficult to plan for a disaster, it is possible to plan for the group of people - and their associated skills - that will be required to coordinate the response. Training plays a key role in disaster governance, providing actors with the tools and knowledge to act when needed. Less obviously, though, is how the drills create a group identity and culture within and across organisations. These individuals are branded as part of a disaster coordination group; they spend time together, learn the language of disaster management (dominated by acronyms 
and terms arising from various disaster management acts and plans), and develop a shared history of past events and experiences, including mock events. Many of the resulting capacities are intangible and difficult to recognise until after a subsequent disaster. In examining the development of disaster governance, it is necessary to consider the establishment of socio-cultural relations among disaster managers. This explicit recognition aligns with the disaster management literature (Krüger et al., 20I5), in which it is often cultural, informal, and social, relations, as well as those based on chance, that withstand disaster impacts and provide the adaptive basis for governance during crises. While the disaster management literature has tended to concentrate on community disaster resilience, the analytical tool of social capital has been expanded here to incorporate disaster governance experts and organisations. The focus of this study is expressly on the people whose response activities during disasters are vital. This fluid and relational understanding (De Laet and Mol, 200o) of disaster management helps one to recognise, and hopefully value, the social dimensions that can be easily overlooked.

Audits of both 'mock' and 'real' disasters are common, yet they frequently occur without expressed recognition of the socio-cultural relations that shape aspects of the events. The respondents noted that not only are policies and practices key components, but also that personal relations, knowledge sharing, and familiarity are essential. The need to share experiences with likeminded people is about creating spaces where emerging relationships and spontaneous dialogue occur in the context of structures and regulations. This is especially important during periods between disasters or when social and institutional memory has faded. The formation and nurturing of social capital among disaster managers, who have the capacity to react and respond to disasters, is therefore a critical part of disaster governance. In addition, the tendency to alter policies and practices without consideration of the implications for socio-cultural relations strikes a cautionary note for those looking to refine disaster management. Monolithic and rigid disaster management systems may be suitable in certain situations, but what has been observed in southeast Queensland is that the process must reflect the dynamic nature of disasters, governance paradigms, responsible organisations, networks, and personnel. The findings of this research suggest that a flexible approach, with grounding in the principles of experiential learning, social learning, and subsidiarity, provides an alternative to rigid forms of disaster governance, and that social-cultural relations are the critical glue, helping to ensure that such an approach is effective.

\section{Acknowledgements}

We would like to dedicate this paper to co-author John Gallina, who sadly passed away just as it was going to press. John was passionate about and dedicated to the implementation of effective and innovative disaster management approaches in Australia. $\mathrm{He}$ is remembered fondly for his great professional and personal contributions. 


\section{Correspondence}

Dr Maria de Lourdes (Marilu) Melo Zurita, School of Geosciences, University of Sydney, Madsen Building, Eastern Avenue, Camperdown NSW 2006, Australia. Telephone: +6I 28627 6385; e-mail: marilumelo@sydney.edu.au

\section{Endnotes}

I Maria de Lourdes (Marilu) Melo Zurita is a Lecturer in Urban Geography at the School of Geoscience, University of Sydney, Australia; Brian Cook is a Senior Lecturer at the School of Geography, University of Melbourne, Australia; Dana C. Thomsen is an Associate Professor in Sustainability Advocacy at the Faculty of Arts, Business and Law, University of the Sunshine Coast, Australia, an Adjunct Professor at the Environmental Sustainability Research Centre, Brock University, Canada, and an Adjunct Professor at the Swedish International Centre of Education for Sustainable Development, Uppsala University, Sweden; Paul G. Munro is a Scientia Research Fellow and Senior Lecturer in the School of Humanities and Languages, University of New South Wales, Australia; Timothy F. Smith is a Professor and the inaugural Director of the Sustainability Research Centre at the University of the Sunshine Coast, Australia, an Adjunct Professor at the Environmental Sustainability Research Centre, Brock University, Canada, and an Adjunct Professor at the Swedish International Centre of Education for Sustainable Development, Uppsala University, Sweden; and John Gallina is the Disaster Management Team Leader at the Sunshine Coast Regional Council, Australia, and a PhD Candidate at the Sustainability Research Centre, University of the Sunshine Coast, Australia.

2 See https://www.legislation.qld.gov.au/LEGISLTN/CURRENT/D/DisastManAo3.pdf (last accessed on I3 September 2017).

\section{References}

Adger, W.N. (2003) 'Social capital, collective action, and adaptation to climate change'. Economic Geography. 79(4). pp. 387-404.

Aldrich, D.P. (20II) 'The power of people: social capital's role in recovery from the I995 Kobe earthquake'. Natural Hazards. 56(3). pp. 595-6II.

Aldrich, D.P. (2012a) Building Resilience: Social Capital in Post-disaster Recovery. University of Chicago Press, Chicago, IL.

Aldrich, D.P. (2012b) 'Social, not physical, infrastructure: the critical role of civil society after the I923 Tokyo earthquake'. Disasters. 36(3). pp. 398-4I9.

Allen, K.M. (2006) 'Community-based disaster preparedness and climate adaptation: local capacitybuilding in the Philippines'. Disasters. 30(I). pp. 8I-IOI.

Australian Bureau of Statistics (2010) 'Regional population growth, Australia, 2009-I0'. Australian Bureau of Statistics, Canberra.

Biggs, R. (20I2) 'Paying for disaster recovery: Australia's NDRRA and the United States' NFIP'. The Australian Journal of Emergency Management. 27(4). pp. 26-30.

Bihari, M. and R. Ryan (20I2) 'Influence of social capital on community preparedness for wildfires'. Landscape and Urban Planning. I06(3). pp. 253-26I.

Britton, N.R. and R.L. Wettenhall (I990) 'Evolution of a disaster "focal point": Australia's natural disaster organisation'. International Journal of Mass Emergencies and Disasters. 8(3). pp. 237-274. 
Col, J. (2007) 'Managing disasters: the role of local government'. Public Administration Review. 67(I). pp. II4-I 24 .

Cook, B. (2015) 'Disaster management culture in Bangladesh: the enrolment of local knowledge by decision makers'. In F. Krüger et al. (eds.) Cultures and Disasters: Understanding Cultural Framings in Disaster Risk Reduction. Routledge, London. pp. I93-207.

Cook, B. and M. Melo Zurita (20I6) 'Planning to learn: an insurgency for disaster risk reduction (DRR)'. International Journal of Disaster Risk Reduction. I9. pp. 265-272.

Council of Australian Governments (20I I) National Strategy for Disaster Resilience: Building our Nation's Resilience to Disasters. Council of Australian Governments, Canberra.

Cutter, S.L., K.D. Ash, and C.T. Emrich (20I4) 'The geographies of community disaster resilience'. Global Environmental Change. 29. pp. 65-77.

De Laet, M. and A. Mol (2000) 'The Zimbabwe bush pump mechanics of a fluid technology'. Social Studies of Science. $30(2)$. pp. 225-263.

Dussaillant, F. and E. Guzmán (20I4) 'Trust via disasters: the case of Chile's 2oro earthquake'. Disasters. $38(4)$. pp. $808-832$

Dynes, R.R. (I983) 'Problems in emergency planning'. Energy. 8(8). pp. 653-660.

Eburn, M. (20II) 'Responding to catastrophic natural disasters and the need for Commonwealth legislation'. Canberra Law Review. Iо (3). pp. 8I-IO2.

Emergency Management Queensland (2012) Queensland District Disaster Management Guidelines. Emergency Management Queensland, Brisbane, QLD.

Fetchik, J. (2012) "Left and right of arc": the legal position of the Australian Defence Force in domestic disaster response using the 2009 "Black Saturday" Victorian bushfires as a case study". The Australian Journal of Emergency Management. 27(2). pp. 3I-36.

Gill, A.M. (I979) 'Fire in the Australian landscape'. Landscape Planning. 6(3-4). pp. 343-357.

Handmer, J., C. Keys, and J. Elliot (1999) Achieving Lasting Change in Multi-organisational Tasks: The Case of Flood Warnings in Australia. State Emergency Services, Sydney.

Hawkins, R.L. and K. Maurer (20IO) 'Bonding, bridging and linking: how social capital operated in New Orleans following Hurricane Katrina'. British Journal of Social Work. 40(6). pp. I777-I793.

Hoffman, S. and A. Oliver-Smith (I999) 'Anthropology and the angry Earth: an overview'. In A. Oliver-Smith and S. Hoffman (eds.) The Angry Earth: Disaster in Anthropological Perspective. Routledge, London. pp. I-I6.

Kaika, M. (2003) 'The water framework directive: a new directive for a changing social, political and economic European framework'. European Planning Studies. I I(3). pp. 299-3I6.

Kendra, J. and T. Wachtendorf (2003) 'Elements of resilience after the World Trade Center disaster: reconstituting New York City's emergency operations centre'. Disasters. 27(I). pp. 37-53.

Kendra, J. and T. Wachtendorf (2007) 'Improvisation, creativity, and the art of emergency management'. In H. Durmaz et al. (eds.) Understanding and Responding to Terrorism. Volume I9. IOS Press, Washington, DC. pp. 324-335.

Krüger, F., G. Bankoff, T. Cannon, B. Orlowski, and E.L. Schipper (eds.) (2015) Cultures and Disasters: Understanding Cultural Framings in Disaster Risk Reduction. Routledge, London.

Leonard, H.B. and A.M. Howitt (20I0) 'Organising response to extreme emergencies: the Victorian Bushfires of 2009'. Australian Journal of Public Administration. 69(4). pp. 372-386.

Majchrzak, A., L.J. Sirkka, and A.B. Hollingshead (2007) 'Coordinating expertise among emergent groups responding to disasters'. Organization Science. I8(I). pp. I47-I6I.

McConnell, A. and L. Drennan (2006) 'Mission impossible? Planning and preparing for crisis'. Journal of Contingencies and Crisis Management. I4(2). pp. 59-70.

McLennan, B.J. and J. Handmer (20I4) Sharing Responsibility in Australian Disaster Management: Final Report for the Sharing Responsibility Project. Bushfire Cooperative Centre, Melbourne. 
Melo Zurita, M., B. Cook, A. March, and L. Harms (20I5a) 'Towards new disaster governance: subsidiarity as a critical tool'. Environmental Policy and Governance. 25(6). pp. 386-398.

Melo Zurita, M. et al. (2015b) 'Reframing water: contesting $\mathrm{H}_{2} \mathrm{O}$ within the European Union'. Geoforum. 65. pp. I70-I78.

Murphy, B.L. (2007) 'Locating social capital in resilient community-level emergency management'. Natural Hazards. 4I(2). pp. 297-3I5.

Nakagawa, Y. and R. Shaw (2004) 'Social capital: a missing link to disaster recovery'. International Journal of Mass Emergencies and Disasters. $22(\mathrm{I})$. pp. 5-34.

Neal, D.M. and B.D. Phillips (I995) 'Effective emergency management: reconsidering the bureaucratic approach'. Disasters. I9 (4). pp. 327-337.

Oliver-Smith, A. (2015) 'Conversations in catastrophe, neoliberalism and the cultural construction of disaster risk. In F. Krüger et al. (eds.) Cultures and Disasters: Understanding Cultural Framings in Disaster Risk Reduction. Routledge, London. pp. 37-52.

Ostrom, E. (20I4) 'Beyond markets and states: polycentric governance of complex economic systems'. In D.H. Cole and M.D. McGinnis (eds.) Elinor Ostrom and the Bloomington School of Political Economy: Polycentricity in Public Administration and Political Science. Volume I. Lexington Books, Lanham, MD. pp. II5-I64.

Pelling, M. (200I) 'Natural disasters'. In N. Castree and B. Braun (eds.) Social Nature: Theory, Practice and Politics. Blackwell Publishing, London. pp. I70-I88.

Pelling, M. (2003) The Vulnerability of Cities: Natural Disasters and Social Resilience. Earthscan, London.

Pelling, M. and C. High (2005) 'Understanding adaptation: what can social capital offer assessments of adaptive capacity?’. Global Environmental Change. I5(4). pp. 308-3I9.

Putnam, R.D. (I995) 'Tuning in, tuning out: the strange disappearance of social capital in America'. PS: Political Science and Politics. 28(4). pp. 664-683.

Putnam, R.D. (2000) Bowling Alone: The Collapse and Revival of American Community. Simon and Schuster, New York, NY.

Queensland Commission of Inquiry (2012) Final Report. March. http://www.floodcommission.qld. gov.au/__data/assets/pdf_file/ooo7/I I698/QFCI-Final-Report-March-20I2.pdf (last accessed on Is September 2017).

Reininger, B.M. et al. (2013) 'Social capital and disaster preparedness among low income Mexican Americans in a disaster prone area'. Social Science and Medicine. 83. pp. 50-60.

Singh-Peterson, L., P. Salmon, C. Baldwin, and N. Goode (2015) 'Deconstructing the concept of shared responsibility for disaster resilience: a Sunshine Coast case study, Australia'. Natural Hazards. 79(2). pp. $755-774$.

Stallings, R.A. and E.L. Quarantelli (I985) 'Emergent citizen groups and emergency management'. Public Administration Review. 45. pp. 93-roo.

State of Queensland (20I6) 'Disaster management arrangements'. Last updated on I7 October 2016. http://www.disaster.qld.gov.au/About_disaster_management/Pages/Disaster-managementarrangements.aspx (last accessed on 26 September 2017).

Sunshine Coast Council (20I4) General Instructions: Sunshine Coast Region Exercise Railbrake Sunshine Coast Local and District Disaster Management Groups, Sunshine Coast.

Susman, S., P.O. O’Keefe, and B. Wisner (I983) 'Global disasters, a radical interpretation'. In K. Hewitt (ed.) Interpretations of Calamity: From the Viewpoint of Human Ecology. Allen and Unwin, London. pp. 263-283.

Szreter, S. and M. Woolcock (2004) 'Health by association? Social capital, social theory, and the political economy of public health'. International Journal of Epidemiology. 33(4). pp. 650-667.

Thomas, M., D. King, D.U. Keogh, A.A. Apan, and S. Mushtaq (20II) 'Resilience to climate change impacts: a review of flood mitigation policy in Queensland, Australia'. Australian Journal of Emergency Management. 26(I). pp. 8-I7. 
Thomsen, D.C. (2008) 'Community-based research: facilitating sustainability learning'. Australasian Journal of Environmental Management. I5(4). pp. 222-230.

Tierney, K. (20I2) 'Disaster governance: social, political, and economic dimensions'. Annual Review of Environment and Resources. 37. pp. 34I-363.

van den Honert, R. and J. McAneney (20II) 'The 201 I Brisbane floods: causes, impacts and implications'. Water. 3(4). pp. II 49-II73.

Varley, A. (ed.) (1994). Disasters, Development and Environment. John Wiley and Sons, Chichester.

Wachtendorf, T. (2013) 'Emergent organizations and networks in catastrophic environments'. In R. Bissell (ed.) Preparedness and Response for Catastrophic Disasters. CRC Press, London. pp. 225-256.

Wettenhall, R.L. (1979) 'Disaster and social science in Australia'. Disasters. 2(4). pp. 24I-245.

Wisner, B. (200I) 'Risk and the neoliberal state: why post-Mitch lessons didn't reduce El Salvador's earthquake losses'. Disasters. 25(3). pp. $25 \mathrm{I}-268$.

Wisner, B. (2003) 'Disaster risk reduction in megacities: making the most of human and social capital'. In A. Kreimer, M. Arnold, and A. Carlin (eds.) Building Safer Cities: The Future of Disaster Risk. The World Bank, Washington, DC. pp. I8I-I96.

Wisner, B., P. Blaikie, T. Cannon, and I. Davis (20I4) At Risk: Natural Hazards, People's Vulnerability and Disasters. Routledge, London.

Wolf, J., W.N. Adger, I. Lorenzoni, V. Abrahamson, and R. Raine (2010) 'Social capital, individual responses to heat waves and climate change adaptation: an empirical study of two UK cities'. Global Environmental Change. 20(I). pp. 44-52.

Wyborn, C, and R.P. Bixler (2OI3) 'Collaboration and nested environmental governance: scale dependency, scale framing, and cross-scale interactions in collaborative conservation'. Journal of Environmental Management. I23. pp. 58-67. 